\title{
Influência da Temperatura Ambiente no Desempenho da Rã-touro, Rana catesbeiana (Shaw, 1802) na Fase de Recria
}

\author{
Luís Gustavo Tavares Braga1, Samuel Lopes Lima²
}

\begin{abstract}
RESUMO - Um experimento foi conduzido com o objetivo de avaliar o efeito da temperatura ambiente no desempenho da rã-touro na fase de recria. Foram utilizadas 405 rãs com peso médio inicial de 37,5 1 1,5 g, em um delineamento experimental inteiramente casualizado três tratamentos $\left(20,2 \pm 0,7^{\circ} \mathrm{C}, 25,1 \pm 0,4^{\circ} \mathrm{C}\right.$ e $\left.30,4 \pm 0,5^{\circ} \mathrm{C}\right)$, cinco repetições (baias) e 27 rãs por baia. $\mathrm{O}$ período experimental foi de 45 dias, sendo dez dias para adaptação das rãs às instalações e ao manejo alimentar. A alimentação foi fornecida diariamente, sendo composta uma por ração comercial de truta com $45 \%$ de proteína bruta e larva de mosca, utilizada como atrativo. Avaliou-se o desempenho dos animais e concluiu-se que a temperatura afetou significativamente o consumo de ração e de larva de mosca e o ganho de peso das rãs, porém os valores de conversão alimentar não diferiram entre as rãs nos três tratamentos. O desenvolvimento da rã-touro está diretamente relacionado com a temperatura ambiente, que influencia o consumo e a utilização do alimento pelos animais.
\end{abstract}

Palavras-chave: desempenho, Rana catesbeiana, rã-touro, temperatura

\section{Influence of Environmental Temperature on the Bullfrog Performance, Rana catesbeiana (Shaw, 1802) in the Growing Phase}

\begin{abstract}
An experiment was conducted to evaluate the effect of environmental temperature on the bullfrog performance in the growing phase. Four hundred and fuve frogs, weighing 37,5 $\pm 1,5$ grams, were assigned to a randomized experimental design with three treatments $\left(20,2 \pm 0,7^{\circ} \mathrm{C}, 25,1 \pm 0,4^{\circ} \mathrm{C}\right.$ and $\left.30,2 \pm 0,5^{\circ} \mathrm{C}\right)$, five replicates (boxes) and 27 frogs in each replicate. The experimental period was of 45 days, being ten days for adaptation of the frogs to the installations and the feeding. The daily feeding comprised one commercial ration of trout with $45 \%$ of crude protein and a fly larva for attraction. The performance of the animals was evaluated and found that the temperature affected significatively affected the consumption of the ration and fly larva and weight gain, however the feed:gain values were not different in the three treatments. The development of the bullfrog is directly related to the environmental temperature, which influences the consumption and utilization of food by the animals.
\end{abstract}

Key Words: bullfrog, performance, Rana catesbeiana, temperature

\section{Introdução}

A rã-touro, Rana catesbeiana (Shaw, 1802), assim como todos os anfíbios, é um animal ectotérmico, ou seja, seu metabolismo está inteiramente dependente da temperatura ambiente. Esta característica influi grandemente na produção comercial, pois, quando a alimentação e a nutrição ocorrem numa faixa de temperatura ótima, ocorre maior consumo de alimento por parte dos animais, possibilitando maior ganho de peso em menor espaço de tempo, que é o principal objetivo de uma criação zootécnica.

Segundo DUELLMAN et al. (1986), não existe evidências de mecanismos internos para produção de calor que aumenta a temperatura corporal dos anfíbios acima da temperatura ambiente. A quantidade de calor metabólico produzida é tão pequena que rapidamente se perde para o ambiente (FROMM, 1956). A relação térmica dos anfíbios com o ambiente envolve perda ou ganho de calor por convecção e condução, radiação térmica do ambiente e perda de calor por evaporação.

O grupo dos anfíbios apresenta grandes variações com relação a tolerância térmica, refletindo os diferentes regimes térmicos de seus habitats. Entretanto, indivíduos podem se aclimatar em diferentes ambientes, o que resultará em alterações dos limites de tolerância.

De acordo com BRATISTROM (1979), o estudo da termorregulação em anfíbios é complicado, devido à necessidade da manutenção de umidade na pele desses animais para garantir as trocas gasosas, po- 
dendo ser comprometida pela economia de água. O comportamento de termorregulação diurno dos Anuros envolve movimentos a favor e contra a exposição aos raios solares assim como entrada e saída da água. Dessa forma, ocorre mudança na magnitude e direção do fluxo de calor entre os animais e o ambiente.

LILLYWHITE (1970) observou que a Rana catesbeiana (rã-touro) promove a termorregulação também por alteração da postura corporal, o que aumenta a superfície de evaporação, podendo chegar a níveis letais de desidratação (BRATISTROM, 1963). Segundo FIGUEIREDO et al. (1999), as rãs-touro se termorregulam, em ambientes confinados, movimentando-se e escolhendo as partes secas ou com água, dependendo da temperatura ambiente. Em temperaturas entre 27 e $29^{\circ} \mathrm{C}$, as visitas à água devem-se às necessidades fisiológicas de hidro e termorregulação ou de digestão e excreção. Em temperaturas mais elevadas, fora da faixa de conforto térmico, as rãs reduzem as temperaturas corporal, aproximando-se da temperatura mais confortável.

Entre os parâmetros abióticos da água, pode-se destacar a temperatura como principal fator a influenciar os processos metabólicos dos animais pecilotérmicos. CHIU e TONG (1979) observaram um aumento de $25 \%$ no consumo de oxigênio acompanhado de uma redução de $125 \%$ do glicogênio hepático quando rãs da espécie Rana tigrina foram tratadas com tiroxina e mantidas a uma temperatura de $25^{\circ} \mathrm{C}$, mas não observaram diferença significativa, tanto no consumo de oxigênio quanto nos níveis de glicogênio hepático, entre os animais tratados com tiroxina e os animais do grupo controle, quando ambos foram mantidos à $15^{\circ} \mathrm{C}$. Os autores concluíram que a atividade metabólica e o efeito da tiroxina são dependentes da temperatura. De acordo com os trabalhos realizados por FIGUEIREDO (1996), os níveis de hormônios da tireóide no plasma estão relacionados com o seu desempenho na temperatura de conforto térmico e podem servir para explicar os melhores ganhos de peso obtidos nesta faixa de temperatura.

BEATTIE et al. (1992) concluíram que a temperatura afeta o desenvolvimento embrionário e o crescimento larval de Rana temporaria. HOFFMANN et al. (1988) estudando o desenvolvimento e metamorfose de girinos de rã-touro em três temperaturas $\left(15,20\right.$ e $\left.25^{\circ} \mathrm{C}\right)$ verificaram que os animais mantidos na temperatura mais elevada apresentaram maior ganho de peso e menor tempo para concluírem a metamorfose. GALDIOLI et al. (1999), trabalhando com temperaturas de 26 a $36^{\circ} \mathrm{C}$, observaram que os girinos apresentaram maior biomassa e sobrevivência, quando mantidos a temperaturas ao redor de $30^{\circ} \mathrm{C}$. A eficiência de digestão nos animais ectotérmicos é afetada pela temperatura ambiente em pelos menos cinco processos: consumo de alimento, nível de secreção de sucos digestivos, atividade enzimática, motilidade do trato gastrintestinal e taxa de absorção intestinal (KAPOOR et al., 1975). De acordo com Joly (1958) e Root (1961), citados por EDWARDS (1971), existe uma variação sazonal na taxa de digestão da rã e parece ser a temperatura o principal fator que interfere nessa taxa, de modo que a secreção gástrica aumenta em temperaturas mais altas, com conseqüente aumento dos processos digestivos.

Diante disso, conduziu-se este trabalho com o objetivo de avaliar a influência da temperatura no desempenho da rã touro (consumo de ração, consumo de larva, ganho de peso e conversão alimentar) entre 37 e 90 gramas de peso vivo.

\section{Material e Métodos}

O experimento foi realizado nas instalações do Ranário Experimental da Universidade Federal de Viçosa, com duração de 35 dias, em três salas, sendo cada uma composta por dez baias. Em cada sala foi estabelecida uma temperatura, correspondendo a cada um dos três tratamentos propostos.

As baias-teste, construídas em placas prémoldadas de cimento (argamassa armada) com dimensões de 140x100x90 cm, possuem um abrigo de madeira, dois cochos e uma canaleta com capacidade para 90 litros. O piso das baias, instalado a $30 \mathrm{~cm}$ sobre uma base de alvenaria com formato retangular, possui um revestimento isolante à base de vermiculita. Entre o piso e a base de alvenaria dispõe-se de um conjunto de resistências elétricas, para promover o aquecimento das baias, ligado a um termostato regulado para a temperatura desejada para o conjunto de baias em cada sala. A temperatura média do conjunto das baias em cada sala foi de $20,2 \pm 0,7^{\circ} \mathrm{C}, 25,1 \pm 0,4^{\circ} \mathrm{C}$ e $30,4 \pm 0,5^{\circ} \mathrm{C}$. Utilizou-se um fotoperíodo $12: 12$ (luz/escuro) com o auxílio de um controlador elétrico de tempo (timer). A iluminação foi feita com lâmpadas incandescentes de 60 watts, utilizandose uma lâmpada por baia, ficando estas situadas a 1,20 $\mathrm{m}$ do piso. 
As janelas, as quais foram revestidas internamente com folhas de alumínio e de isopor com um centímetro de espessura, permaneceram abertas durante o dia para favorecer a renovação do ar e foram fechadas às $18 \mathrm{~h}$ para evitar que a variação da temperatura externa, durante à noite, alterasse a temperatura das baias.

Foram utilizados 405 rãs com peso inicial médio de $37,5 \pm 1,5$ gramas em um delineamento inteiramente casualizado com três tratamentos $\left(20^{\circ} \mathrm{C}, 25^{\circ} \mathrm{C}\right.$ e $30^{\circ} \mathrm{C}$ ), cinco repetições e 27 animais por baia, que foi considerada a unidade experimental.

As rãs foram marcadas segundo o método de MARTOF (1953), durante um período de adaptação de dez dias para permitir a pesagem individual, e utilizou-se uma solução de permanganato de potássio como cicatrizante. A alimentação, fornecida a vontade, foi composta de uma ração comercial para truta com 45\% de proteína e de larva de mosca (Musca domestica) a uma proporção de $10 \%$ da ração na primeira semana e de $5 \%$ durante as quatro semanas subsequentes quando o experimento foi encerrado, com os animais atingindo um peso médio final de $83,45 \pm 9,70$ gramas. A larva de mosca foi produzida no moscário instalado nas dependências do Ranário Experimental utilizando a técnica descrita por ALEIXO et al. (1984).

Para registrar o consumo de alimento, antes da limpeza das baias foram coletadas as sobras de alimento, que posteriormente passavam por um processo de separação de larva e ração, utilizando um jogo de peneiras com diâmetro de $3 \mathrm{~mm}$ e bandejas plásticas, de modo que as larvas passavam pelos furos das peneiras, caindo no interior das bandejas. As pupas foram coletadas manualmente com o auxílio de uma pinça. A ração foi então levada para a estufa a $50^{\circ} \mathrm{C}$ por 24 horas enquanto que a larva de mosca e pupa foram imediatamente pesadas em balança analítica de precisão.

Avaliou-se o desempenho dos animais individualmente por meio de uma pesagem semanal. As análises estatísticas foram feitas segundo o programa SAEG (UFV, 1993).

O modelo estatístico utilizado foi:

$$
\mathrm{Y}_{\mathrm{ij}}=\mu+\mathrm{E}_{\mathrm{i}}+\mathrm{e}_{\mathrm{ij}}
$$

em que: $Y_{i j}=$ observações relativas a ganho de peso, consumo alimentar, conversão alimentar no tratamento i e repetição $\mathrm{j} ; \mu=$ média geral; $\mathrm{E}_{\mathrm{i}}=$ efeito da temperatura $\mathrm{i}$, em que $\mathrm{i}=20,2 \pm 0,7^{\circ} \mathrm{C}, 25,1 \pm 0,4^{\circ} \mathrm{C}$ e $30,4 \pm 0,5^{\circ} \mathrm{C} ; \mathrm{e}_{\mathrm{ij}}=$ erro aleatório.

\section{Resultados e Discussão}

Os resultados de consumo de larva de mosca e ração, ganho de peso, conversão alimentar e taxa de mortalidade da rãs touro encontram-se na Tabela 1 . Observou-se efeito significativo $(\mathrm{p}<0,05)$ da temperatura sobre o consumo médio de alimento (CMA), que foi menor para os animais mantidos a $20,2^{\circ} \mathrm{C}$ em relação aos dos outros dois tratamentos. Como o consumo de alimento está relacionado diretamente ao metabolismo da rã, que por sua vez é influenciado pela temperatura ambiente, pode-se inferir que a faixa de temperatura entre 25,1 a $30,4^{\circ} \mathrm{C}$ revelou ser a mais adequada para a rã touro nesta fase de desenvolvimento.

$O$ baixo consumo de alimento verificado no tratamento, correspondente à temperatura de $20,2^{\circ} \mathrm{C}$, ocorreu em razão da mudança de comportamento termorregulatório dos animais que permaneceram mais tempo sob os abrigos, diminuindo assim a freqüência com que se alimentavam. Os anfíbios, assim como muitos outros organismos, compensam parcialmente as mudanças térmicas do ambiente através da aclimatação que provoca vários ajustes bioquímicos e fisiológicos. Este procedimento é a principal estratégia utilizada para reproduzir as mudanças ocorridas na temperatura ambiente (MILLER e ZOGBHY, 1986).

Tabela 1 - Valores médios de desempenho e taxa de
mortalidade da rã touro submetida a três
temperaturas ambiente* Temperatura das baias $\left({ }^{\circ} \mathrm{C}\right)$ Box temperatures

\begin{tabular}{|c|c|c|c|c|}
\hline Item & 20 & 25 & 30 & $\begin{array}{l}\mathrm{CV} \\
(\%)\end{array}$ \\
\hline $\begin{array}{l}\text { Ganho de peso }(\mathrm{g}) \\
\text { Weight gain }\end{array}$ & $32,48^{a}$ & $52,62^{b}$ & $52,54^{\mathrm{b}}$ & 9,99 \\
\hline $\begin{array}{l}\text { Consumo de ração }(\mathrm{g}) \\
\text { Ration intake }\end{array}$ & $41,70^{\mathrm{a}}$ & $69,15^{\mathrm{b}}$ & $65,81^{\mathrm{b}}$ & 9,39 \\
\hline $\begin{array}{l}\text { Cons. de larva mosca }{ }^{1}(\mathrm{~g}) \\
\text { Fly larva intake }\end{array}$ & $4,72^{a}$ & $6,74^{\mathrm{b}}$ & $7,78^{\mathrm{b}}$ & 7,18 \\
\hline $\begin{array}{l}\text { Consumo de alimento }(\mathrm{g}) \\
\text { Feed intake }\end{array}$ & $46,42^{\mathrm{a}}$ & $75,89^{b}$ & $73,59^{\mathrm{b}}$ & 9,45 \\
\hline $\begin{array}{l}\text { Conversão alimentar } \\
\text { Feed:gain ratio }\end{array}$ & $1,43^{\mathrm{a}}$ & $1,46^{\mathrm{a}}$ & $1,40^{\mathrm{a}}$ & 9,45 \\
\hline $\begin{array}{l}\text { Taxa de mortalidade }(\%) \\
\text { Mortality rate }\end{array}$ & $13^{\mathrm{a}}$ & $10^{\mathrm{a}}$ & $14^{\mathrm{a}}$ & 6,99 \\
\hline
\end{tabular}

* Médias seguidas das mesmas letras na mesma linha, não diferem $(p>0,05)$ pelo teste SNK.

*Means followed by same letter within a row, do not differ $(p>.05)$ by SNK test. 
Com relação ao consumo de larva de mosca diferenciado, observado entre as rãs dos tratamentos de 25 e $30^{\circ} \mathrm{C}$, foi verificado um ressecamento da ração com o aumento da temperatura, e neste caso, sem a umidade que é essencial para seu desenvolvimento, as larvas tentaram sair do cocho a procura de um outro substrato ficando mais visíveis às rãs deste último tratamento, aumentando assim o seu consumo, já que as rãs têm preferência por alimento em movimento. Em razão do aumento do consumo de larvas, as rãs diminuíram o de ração na temperatura de $30^{\circ} \mathrm{C}$.

Por outro lado no tratamento correspondente a temperatura de $20^{\circ} \mathrm{C}$, as larvas de mosca imergiram mais rapidamente na ração na tentativa de obter maior quantidade de calor, além da fotofobia que lhe é característica, fato este que aliado ao menor metabolismo dos animais explica o menor consumo de larva de mosca.

A exemplo do CMA, o ganho de peso médio (GPM) das rãs também foi influenciado significativamente $(\mathrm{p}<0,05)$ pela temperatura ambiente, sendo encontrado valores iguais entre os tratamentos de 25,1 e $30,4^{\circ} \mathrm{C}$ e superiores aos do tratamento de $20,2^{\circ} \mathrm{C}$. Esses resultados foram semelhantes àqueles encontrados por FIGUEIREDO (1996), quando avaliou o desempenho da rã-touro em gaiolas, utilizando diferentes temperaturas ambiente e constatou que a temperatura adequada para recria desse animal foi estimada entre o mínimo de $26,9^{\circ} \mathrm{C}$ e o máximo de $28,2^{\circ} \mathrm{C}$, entretanto, FONTANELO et al. (1992) concluíram que temperaturas mais elevadas (médias máximas acima de $40^{\circ} \mathrm{C}$ ) observadas em baias do sistema tanque-ilha foram responsáveis pelo melhor desempenho das rãs.

Não se observou efeito $(\mathrm{P}>0,05)$ da temperatura sobre a conversão alimentar (CA) dos animais, pois foi mantida a proporcionalidade entre a quantidade de alimento ingerido e o ganho de peso das rãs nos três tratamentos. $\mathrm{O}$ valor de $\mathrm{CA}$ encontrado neste trabalho foi semelhante ao encontrado por LIMA (1991), em estudo com a mesma espécie. A análise desse resultado revelou que as mudanças nos valores de GPM. dos animais ocorreram em razão da variação no consumo de alimento. Avaliando os resultados de desempenho (consumo de alimento, ganho de peso e conversão alimentar) obtidos neste experimento pode-se deduzir que o desenvolvimento da rã touro na fase pós-metamórfica está diretamente relacionado com a temperatura ambiente a que os animais estão expostos.

Não se verificou efeito $(\mathrm{p}>0,05)$ da temperatura ambiente sobre a taxa de mortalidade dos animais.
As porcentagens de mortalidade observadas neste trabalho (10 a 14\%) foram semelhantes àquelas encontradas por LIMA e AGOSTINHO (1992).

\section{Conclusões}

Com base nos dados diários de consumo de ração e de larva de mosca e ganho de peso, concluiu-se que a faixa de temperatura entre 25,1 e $30,4^{\circ} \mathrm{C}$ correspondeu ao melhor crescimento da rã-touro entre 37 e $90 \mathrm{~g}$.

O desenvolvimento da rã touro está diretamente relacionado com a temperatura ambiente, pois este parâmetro influencia o consumo e a utilização do alimento pelos animais.

\section{Referências Bibliográficas}

ALEIXO, R.C., LIMA, S.L., AGOSTINHO, C.A. 1984. Criação da mosca doméstica para suplementação alimentar de rãs. Viçosa, MG: UFV (Informe Técnico, 46). 11p.

BEATTIE, R.C., TYLER-JONES, R., BAXTER, M.J. 1992. The effects of ph, aluminiun and temperatura on the embryonic development of the european frog, Rana temporaria. Journal Zool. Lond., 228: 557-570.

BRATISTROM, B.H. 1963. Preliminary review of the thermal requiriments of amphibians. Ecology, 11:238-255.

BRATISTROM, B.H. 1979. Amphibiam temperature regulation studies in the field and laboratory. Amer. Zool., 19:345-356.

CHIU, K.W., TONG, W.C.M. 1979. Effects os temperature acclimation and tyroxine injection on glycogen storage and oxygen consumption in the frog, Rana tigrina. Comparative Biochemistry and Physiology, 63A: 551-553.

DUELLMAN, W.E., TRUEB, L. 1986. Biology of amphibians. New York-NY: McGraw-Hill Book Company. 670p.

EDWARDS, D.J. 1971. Effect of temperature on rate of passage of food through the alimentar canal of the plaice Pleuronectes platessa L. Eish. Biol., 3:433-439.

FIGUEIREDO, M.R.C. Influência dos fatores ambientais sobre o desempenho da rã-touro (Rana catesbeiana Shaw, 1802) em gaiolas. Viçosa, MG: UFV, 1996. 151p. Dissertação (Doutorado em Zootecnia) - Universidade Federal de Viçosa, 1996.

FIGUEIREDO, M.R.C., AGOSTINHO, C.A., BAÊTA, F.C et al. Comportamento termorregulador da rã-touro (Rana catesbeiana Shaw, 1802) submetida a estresse térmico ambiental. In: REUINÃO ANUAL DA SOCIEDADE BRASILEIRA DE ZOOTECNIA, 26, 1999, Porto Alegre-RS. Anais... Porto Alegre, 1999. PEQ 26.

FONTANELLO, D., WIRZ, R.R., ARRUDA SOARES, H. et al. Comparação do desenvolvimento ponderal de rã-touro (Rana catesbeiana Shaw, 1802), e do custo de produção de quatro sistemas de engorda: Confinamento, Anfigranja, Tanque-ilha e gaiolas. In: ENCONTRO NACIONAL DE RANICULTURA, 7, 1992, Rio de Janeiro-RJ. Anais ... Rio de Janeiro: ARERJ. 1992, p.40-64.

FROMM, P.O. 1956. Heat production of frogs. Physiology Zoology, 29:234-240.

GALDIOLI, E.M., HAYASHI, C., FURUYA, V.R. Utilização de diferentes temperaturas no cultivo de girinos de rã-touro (Rana catesbeiana Shaw, 1802) em aquários experimentais. 
In: REUINÃO ANUAL DA SOCIEDADE BRASILEIRA DEZOOTECNIA, 26,1999, Porto Alegre-RS, 1999. Anais... Porto Alegre. PEQ 14.

HOFFMANN, D.F., LEBOUTE, E.M., SOUZA, S.M.G. Efeito da temperatura no ganho de peso de girinos de rã-touro, Rana catesbeiana Shaw, 1802. In: SIMPÓSIO LATINOAMERICANO, 6.; SIMPÓSIO BRASILEIRO DE AQÜICULTURA, 5., 1988, Florianópolis-SC. Anais..., Florianópolis, 1988. p.799-803.

KAPOOR, B.G., SMITH, H., VERIGHINA, I.A. 1975. The alimentary canal and digestion in teleosts. Adv. Mar. Biol., 13:109-239.

LILLYWHITE, H.B. 1970. Behavior thermoregulation in the bullfrog, Rana catesbeiana. Copeia p.158-168.

LIMA, S.L. 1991. Ranicultura brasileira: realidades e perspectivas. Panorama da Aqüicultura, 1(6).
LIMA, S. L., AGOSTINHO, C. A. 1992. A tecnologia de criação de rãs. Viçosa, MG: UFV. 168p.

MARTOF, B.S. 1953. Territorialy in the green frog, Rana clamitans. Ecology, 34(1):166-174.

MILLER, K., ZOGHBY, G.M. 1986. Thermal acclimation of locomotor performance in Anuran Amphibians. Can. J. Zool., 64:1956-1960.

UNIVERSIDADE FEDERAL DE VIÇOSA - UFV. 1993. Central de processamento de dados UFV/CPD. Manual de utilização do programa SAEG (Sistema para análises estatísticas e genéticas). Viçosa, MG, UFV. 59p.

Recebido em: 08/02/00

Aceito em: 26/06/01 